\title{
Prevalence of dementia and other psychiatric morbidities among geriatric population of Salagame primary health centre in Hassan district, Karnataka, India
}

\author{
Sumana M.*, C. Y. Sreelatha, Anjan Sreeranga, B. Arpitha, S. P. Akshatha, H. D. Anand
}

Department of Community Medicine, Hassan Institute of Medical Sciences, Hassan, Karnataka, India

Received: 15 April 2016

Accepted: 22 April 2016

\author{
*Correspondence: \\ Dr. Sumana M., \\ E-mail: sumana_prasad@yahoo.com
}

Copyright: (C) the author(s), publisher and licensee Medip Academy. This is an open-access article distributed under the terms of the Creative Commons Attribution Non-Commercial License, which permits unrestricted non-commercial use, distribution, and reproduction in any medium, provided the original work is properly cited.

\begin{abstract}
Background: Depression and dementia are mental health problems that are encountered in elderly in india. it is imperative for us to recognize these symptoms in elderly and treat them appropriately. Thus we intended to study the prevalence and risk factors of depression and dementia in geriatric population in selected field practice area of Hassan Medical College.

Methods: A community based descriptive study was conducted among 231 individuals in geriatric age group aged 60 and above, over a period of 2 months. The sample size was estimated based on the prevalence of depression as $31 \%$ stated in one of the large community based study using similar scale. Geriatric Depression Scale-15 (GDS-15) was used to screen for depressive disorders and Barthel Index to grade their physical activity. Dementia among elderly was screened with a vernacular adaptation of the Hindi Mental State Examination tool (HMSE).

Results: Among 231 individuals, 150 (64.93\%) were females and 81 (35.06\%) were males. 45.88\% of them had no formal education. Among 231 elderly individuals, 13 cases of dementia were identified with a prevalence rate of $5.6 \%$. Total prevalence of depression was found to be $60.17 \%$. Higher prevalence of dementia was found in females $(6.6 \%)$, age above 80 years $(18.7 \%)$, unemployed and labourers $(7.4 \%)$, illiterates $(7.4 \%)$, low SES (6.5\%) and dependents $(7.5 \%)$.

Conclusions: Depression and dementia are important health problems of the elderly population. Simple tools used in this study can be used at primary health care settings for early identification of dementia and depression in the elderly population.
\end{abstract}

Keywords: Barthel index, Geriatric depression, GDS-15, HMSE, Dementia, Hassan

\section{INTRODUCTION}

India is in a phase of demographic transition. There has been a sharp increase in number of elderly persons from 1991 to 2011 and it has been projected that by the year 2050 , the number of elderly would rise to 324 million. ${ }^{1}$ On account of better education, health facilities and increase in life expectancy, the percentage of elderly population $(60+)$ in rural and urban areas have gone up from 5.3 to 5.7 percent and 6.0 to 8.0 percent respectively during the period. ${ }^{2}$
Depression and dementia are the two important mental health problems that are encountered in elderly in India, while depression in old age is quite prevalent. It is a popular misconception that depression and dementia is a part of the normal ageing process yet they can't be considered as physiological and inevitable part of ageing. They are commonly associated with medical illness and also linked to increased morbidity and mortality as it can worsen underlying medical disorders. These untreated mental illnesses in elderly are associated with a poor 
quality of life, difficulty with social and physical functioning.

Dementia prevalence in the studies conducted across various parts from India showed 33.6/1000 in southern India $^{3}, 24.4 / 1000$ in western India ${ }^{4}, 13.3 / 1000$ in northern India $^{5}$. It is estimated that over 3.7 million people are affected by dementia in our country. This is expected to double by 2030 . Despite the magnitude, there is gross ignorance, neglect and scarce services for people with dementia and their families. ${ }^{6}$ Depression prevalence has ranged from $5 \%$ to $58 \%$ in various studies across the country. ${ }^{7-11}$ Globally prevalence of depression is $10-20 \%$ and Dementia is 3\%. In India prevalence of dementia varies from $0.9-7.5 \% .^{12}$

Depression is a mental state characterized by feeling of sadness, loneliness, despair, no self-esteem, and selfreproach. Accompanying signs include psychomotor retardation or at times agitation, withdrawal from interpersonal contact and vegetative symptoms, such as insomnia and anorexia. ${ }^{3}$

Dementia is a mental disorder characterized by general impairment in intellectual functioning without clouding of consciousness, characterized by failing memory, difficulty with calculation, distractibility, alterations in mood and affect, impaired judgment and abstractions, reduced feasibility with language and disturbance of orientation. $^{6}$

Depression and dementia account for more than half of the psychiatric morbidity in Indian elderly. It has been observed to be more common in females, low socioeconomic status, uneducated and unemployed. Various studies worldwide have reported increased disability, poor health care utilization and increased cost of health services. ${ }^{6}$ Depressive symptoms are significant risk factors for cardiovascular as well as noncardiovascular mortality. With the growing number of elderly in the Indian population, the burden of depression is going to be huge on the society. Thus it is imperative for the physician to recognize the symptoms of depression in elderly and treat them appropriately.

We need to develop community-based interventions for management of mental health conditions like dementia and depression in late life. The effectiveness of these interventions needs to be established. It is important to identify risk factors for depression and dementia in our population. We could then try and modify these factors to reduce the prevalence of these conditions. This study intended to identify the disease load and risk factors of depression and dementia in geriatric population.

\section{METHODS}

A Cross sectional study was carried out for a period of three months from January 2011 to March 2011. Study area included villages coming under Salagame Primary
Health Centre which is the field practice area of the Community Medicine Department. Total population of the study area is 27151, among which Geriatric population accounted 5,418. Sample size was calculated based on the prevalence rate of a large community based study in India: $31 \% .^{13}(p=0.031, q=0.069,1=0.062)$. The Sample size was estimated to be 231 elderly Individuals.

Salagame has 10 sub centres. By random sampling 6 sub centers were selected, 40 elderly from each sub centre were randomly selected. Study population included all the elderly population aged more than 60 years residing in the study area for past six months. Individuals with serious or terminal illness, clear History of Thyroid disorders, HIV infection, and brain tumours were the excluded from the study.

Along with various socio demographic factors, presence of high blood pressure, diabetes mellitus, cardiac disease, cancer, head injury, fits or any psychiatric disorder was assessed and cross checked with Caregivers.

After reviewing previous studies semi-structured questionnaire was designed keeping in mind the objectives of the study and study variables. Data collection was done by interview schedule. A door to door survey was done in the selected villages of Salagame. Geriatric Depression Scale-15 (GDS-15) was used to screen for depressive disorders and Barthel Index to grade their physical activity. Screening for dementia was done with a vernacular adaptation of the Hindi Mental State Examination (kannada). The tool was translated and validated independently by three people and one of them was psychiatrist of our hospital.

Statistical Analysis was done using Microsoft Excel for data entry and Epi Info software for analysis. Descriptive statistics was used to summarize and Chi square test to co-relate risk factors with prevalence of depression and dementia.

The following study tools were used to screen for dementia, depression and physical activity.

Hindi Mental State Examination (HMSE) ${ }^{14}$; this test consists of 22 items, which test different components of intellectual capability. The items cover several areas of cognitive functioning such as orientation to time (1-5) and place (6-10), memory (11), attention and concentration (12-16), recognition of objects (17-18), language function (19), both comprehension and expressive speech (21), motor functioning and praxis (20\&22). It is relatively simple to administer and provides a quick, brief index of the subject's current level of functioning. It is a modified version of the Mini Mental State Examination, <24/30 suggestive of dementia (sensitivity $81 \%$, specificity 93\%). Spuriously low in people with low educational level, low SES, poor language skills, illiteracy, impaired vision and not sensitive in people with higher educational background. 
Scores:1= Correct answer, 0=Wrong answer; Grading, Normal: 24-30 Mild: 18-23, Moderate: 10-17 Severe: $<10$.

GDS-Geriatric Depression Scale ${ }^{15}$, we have used GDSSF, a short form of GDS which has been extensively used with the older population. The conclusions of the study were based on a questionnaire, where individuals were required to either state 'yes' or 'no' to a set of 15 questions. The GDS may be used with healthy, medically ill and mild to moderately cognitively impaired older adults. It has been extensively used in community, acute and long-term care settings.

Score 1 point for each bolded answer. A score of 5 or more suggests depression. Score of 5 is considered to be the best cut-off point for diagnosing depression in an elderly population, with sensitivity $=80.5 \%$ and specificity $=75.0 \%$. Factor analysis of the GDS-15 revealed 4 factors: a cognitive (thought content), an affective, a functional and a factor that reflects helplessness and fear for the future. The two diagnostic groups differed on all 4 factors scores at p-value $<0.001$. Grading: 0-4 normal, 5-10 moderate, 11-15 severe.

\section{Barthel index ${ }^{16}$}

This questionnaire consisted of 10 items which were used to grade the status of activity of daily living. Scoring criteria: Total Score $=100$ Dependant $<80$.

\section{RESULTS}

Two hundred and thirty one elderly people formed the study population of which one hundred and fifty were females and eighty one were males. About $7.35 \%$ were living alone and $45.88 \%$ had no formal education. About half of the elderly were BPL card holders.11 (5\%) were dependent on family members for day today activities of living according to Barthel index (Table 1).

Out of 231 elderly populations screened for dementia using Hindi Mental State Examination (HMSE) 13 scored 24 and below, a prevalence rate of 5.6\% (Table 2). All the thirteen elderly individuals were referred to psychiatry department for further evaluation.

Higher prevalence of dementia was observed as age advances. Dementia was more prevalent among females (Table 3), (Figure 1). The mean age among dementia patients was 75 years. Higher prevalence of dementia was found in females $(6.6 \%)$, age above 80 years $(18.7 \%)$, unemployed and labourers $(7.4 \%)$, illiterates $(7.4 \%)$, low SES (6.5\%) and dependents (7.5\%). Dementia was prevalent in $16.9 \%$ of depressive geriatric patients (Table 4).

Among 231 elderly individuals screened for depression using GDS-15, prevalence of depression was found to be $60.17 \%$. Higher prevalence of depression was found to be significant in females (66\%), age above 80 years $(93.75 \%)$ (Figure 2), unemployed (90.9\%), illiterates (77.35\%), low socio economic status (63.9\%), h/o known hypertension $(73.8 \%)$, and h/o known diabetes mellitus $(89.47 \%$ ) (Table 5, Table 6).

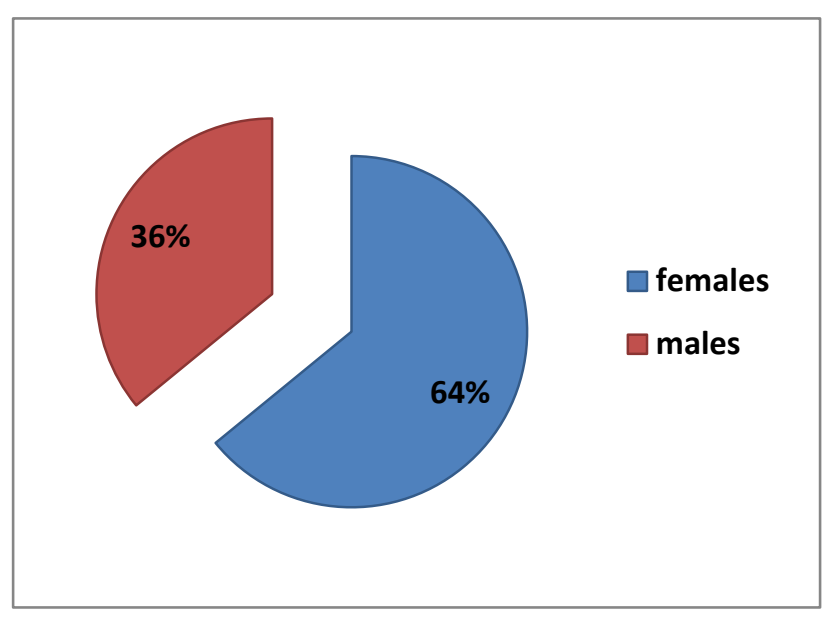

Figure 1: Prevalence of dementia according to gender.

Table 1: Socio demographic profile of Study subjects $(\mathbf{n}=231)$.

\begin{tabular}{|lc|}
\hline Socio demographic characteristics & n (\%) \\
\hline Gender & $81(35)$ \\
\hline Male & $150(65)$ \\
\hline Female & \\
\hline Age group & $104(45)$ \\
\hline $60-65$ & $49(21)$ \\
\hline $66-70$ & $32(14)$ \\
\hline $71-75$ & $30(13)$ \\
\hline $76-80$ & $16(7)$ \\
\hline$\geq 81$ & \\
\hline Educational status & $106(46)$ \\
\hline Illiterate & $53(23)$ \\
\hline Primary & $51(22)$ \\
\hline Secondary & $21(9)$ \\
\hline $10^{\text {th }}$ std and above & $66(28)$ \\
\hline Occupation & $127(55)$ \\
\hline Housewife & $11(5)$ \\
\hline Agriculture & $16(7)$ \\
\hline Labour & $11(5)$ \\
\hline Currently not working & $220(95)$ \\
\hline Others & $122(53)$ \\
\hline Socio economic status & \\
\hline Class 1-3 & \\
\hline Class 4 & \\
\hline Class 5 & \\
\hline Status of activity of daily living (Barthel index) \\
\hline Dependent & $118)$ \\
\hline Independent & \\
\hline & \\
\hline
\end{tabular}




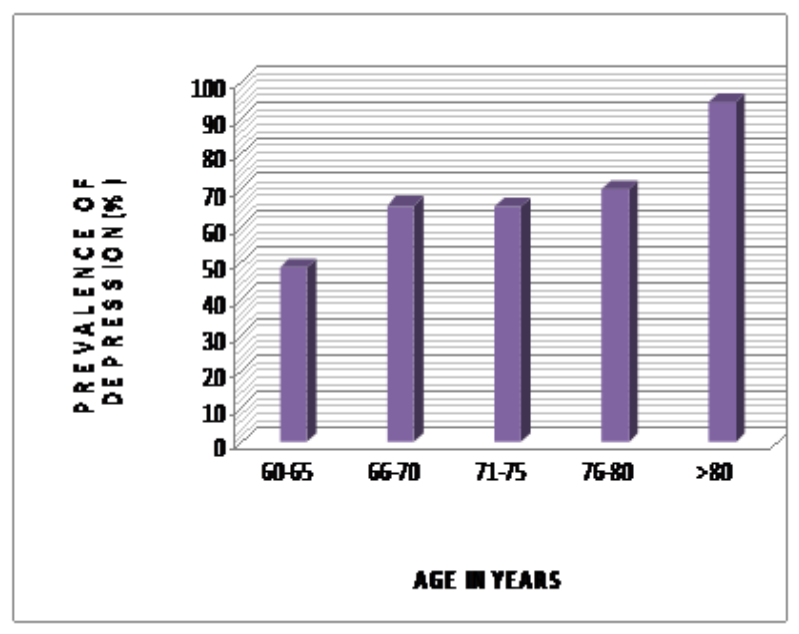

Figure 2: Prevalence of depression according to age.

Table 2: Prevalence of depression and dementia among study subjects.

\begin{tabular}{|llll|}
\hline Disorder & Present & Absent & Prevalence (\%) \\
\hline Depression & 139 & 82 & $60.17 \%$ \\
\hline Dementia & 13 & 218 & $5.6 \%$ \\
\hline
\end{tabular}

Table 3: Prevalence of dementia in study subjects according to age.

\begin{tabular}{|lllll|}
\hline $\begin{array}{l}\text { Age } \\
\text { (years) }\end{array}$ & Present & Absent & $\begin{array}{l}\text { Total } \\
(\mathbf{n})\end{array}$ & $\begin{array}{l}\text { Prevalence } \\
(\%)\end{array}$ \\
\hline $60-65$ & 3 & 101 & 104 & $2.8 \%$ \\
\hline $66-70$ & 1 & 48 & 49 & $2.0 \%$ \\
\hline $71-75$ & 2 & 30 & 32 & $6.2 \%$ \\
\hline $76-80$ & 4 & 26 & 30 & $13.3 \%$ \\
\hline$>80$ & 3 & 13 & 16 & $18.7 \%$ \\
\hline
\end{tabular}

Table 4: Gender wise prevalence of depression.

\begin{tabular}{|lllll|}
\hline Gender & \multicolumn{2}{c}{ Depression } & Total & $\begin{array}{l}\text { Prevalence } \\
(\%)\end{array}$ \\
\hline Male & 40 & 41 & 81 & 49.38 \\
\hline Female & 99 & 51 & 150 & 66 \\
\hline$\chi^{2}=5.3869, \quad \mathrm{df}=1$, & $\mathrm{p}=<0.05$ & & \\
\hline
\end{tabular}

Table 5: Prevalence of dementia among subjects with depression.

\begin{tabular}{|lllll|}
\hline \multirow{2}{*}{ Dementia } & \multicolumn{2}{l}{ Depression } & Total & $\begin{array}{l}\text { Prevalence } \\
\text { \% }\end{array}$ \\
\cline { 2 - 5 } & Present & Absent & & $\mathbf{7 6 . 9 \%}$ \\
\hline Present & 10 & 03 & $\mathbf{1 3}$ & $\mathbf{4 1 . 5 \%}$ \\
\hline Absent & 49 & 69 & $\mathbf{1 1 8}$ & $\mathbf{4}$ \\
\hline $\mathrm{X}^{2}=5.92$, & $\mathrm{df}=1$, & $\mathrm{p}=<0.05$ & & \\
\hline
\end{tabular}

Table 6: Factors influencing depression among study subjects.

\begin{tabular}{|c|c|c|c|c|c|c|c|}
\hline \multirow{2}{*}{\multicolumn{2}{|c|}{ Parameters }} & \multicolumn{2}{|c|}{ Depression } & \multirow{2}{*}{ Total } & \multirow{2}{*}{ Prevalence $(\%)$} & \multirow{2}{*}{$x^{2}$} & \multirow{2}{*}{$\begin{array}{l}\mathbf{P} \\
\text { value }\end{array}$} \\
\hline & & Absent & Present & & & & \\
\hline \multirow{4}{*}{ Education } & Illiterate & 82 & 24 & 106 & 77.35 & \multirow{4}{*}{27.5065} & \multirow{4}{*}{$<0.05$} \\
\hline & Primary & 29 & 24 & 53 & 54.71 & & \\
\hline & Higher primary & 21 & 31 & 52 & 40.38 & & \\
\hline & $\begin{array}{l}\text { Secondary and } \\
\text { above }\end{array}$ & 7 & 13 & 20 & 35 & & \\
\hline \multirow{3}{*}{$\begin{array}{l}\text { Socio } \\
\text { economic } \\
\text { status }\end{array}$} & class $1-4$ & 6 & 14 & 20 & 30 & \multirow{3}{*}{8.4161} & \multirow{3}{*}{$<0.05$} \\
\hline & Class 5 & 55 & 34 & 89 & 61.7 & & \\
\hline & Class 6 & 78 & 44 & 122 & 63.9 & & \\
\hline \multicolumn{2}{|c|}{ Hypertension } & 31 & 11 & 42 & 73.8 & 0.6 & $<0.05$ \\
\hline \multicolumn{2}{|c|}{ Diabetes mellitus } & 17 & 2 & 19 & 89.47 & 3.7734 & $<0.05$ \\
\hline \multirow{2}{*}{$\begin{array}{l}\text { Activity of } \\
\text { daily living }\end{array}$} & Dependent & 9 & 3 & 12 & 75 & \multirow{2}{*}{6.1442} & \multirow{2}{*}{$>0.05$} \\
\hline & Independent & 130 & 89 & 219 & 59.36 & & \\
\hline \multicolumn{2}{|c|}{$\mathrm{H} / \mathrm{O}$ mental illness } & 1 & 2 & 3 & 33.33 & 0.3753 & $>0.05$ \\
\hline \multicolumn{2}{|c|}{ Living with children } & 109 & 76 & 185 & 58.9 & 0.1313 & $>0.05$ \\
\hline
\end{tabular}

\section{DISCUSSION}

Dementia and depression are emerging health problems of the elderly. They are important public health conditions which need serious rethinking. Understanding their risk factors can help us prevent further rise in the incidence. The following study aimed to estimate the prevalence and understand the risk factors of both dementia and depression among elderly population.

In our study we have used the Barthel Index, GDS-15, vernacular adoption of Hindi Mental State Examination (HMSE) tools to assess Status of activity of daily living, geriatric depression and dementia. According to Linda G 
Marc et al., the psychometric properties of the GDS-15 had sensitivity $80.5 \%$, specificity $75.0 \%$, with optimal cut-off values $5 / 6^{17}$ and according to Pandav et al HMSE $(\leq 24)$ has sensitivity of $81.3 \%$, specificity of $93.4 \%$, PPV of $8.0 \%$, and NPV of $99.9 \%$. $^{18}$

In the present study $5.6 \%$ of elderly were found to have dementia when screened with vernacular adaptation of Hindi Mental State Examination (HMSE). Several community based studies in different parts of the country both in rural and urban areas have found similar prevalence of $3.3 \%^{3}, 2.7 \%^{19}, 3.8 \%^{20}, 8.4 \%^{4}$. Age, low education and female gender showed increased risk of dementia in our study.

Total prevalence of depression was found to be $60.17 \%$. Nandi et al. (1997) in a rural community of Gambhirgachi and Paharpur villages, West Bengal found prevalence of depression as $52.2 \% .{ }^{21}$ A recent study using similar Geriatric Depression Scale reported a prevalence of $45.9 \%$. Similar rates were reported from Andra Pradesh $^{11}$ and Uttar Pradesh. ${ }^{23}$ Some of the studies have reported lower prevalence of Geriatric Depression also. $^{7,24}$ This variation can be explained because of different study settings.

In the present study depression was more common as age advanced. Age above 80 years showed a higher prevalence which was statistically significant, similar to studies done in Nellore ${ }^{7}$, Ludhiana ${ }^{25}$ and Manipal ${ }^{26}$. Elderly females showed higher prevalence of Depression than men similar to the other studies. ${ }^{7,11,26}$ Lack of recreation, being dependent on spouse and children, more emotionally attached to the family, neglect, loss of spouse because of higher life expectancy all could be the reasons of higher prevalence.

Illiteracy, low socio economic status (63.9\%). Morbidities like hypertension (73.8\%), and Diabetes mellitus $(89.47 \%)$ were other risk factors which were associated with depression. Many studies have reported that the illiteracy, low socio economic status, chronic illness all are independent predictors of Geriatric depression. $^{7,11,26,27}$

As quoted by Steffens DC et al and Ganguli et al many studies have correlated Depression and Dementia, stating Dementia is more common among elderly with depression. There are intriguing reports that suggest depression might itself increase the risk of dementia. ${ }^{28,29}$ In our study too we found prevalence of dementia was significantly higher among subjects with depression. It is always clinically appropriate to treat depression to reduce suffering, which itself is a major cause of morbidity and mortality. ${ }^{30}$ Perhaps in a few years we will know whether treating depression, as an added bonus, will also stave off dementia. $^{29}$

Limitation of our study was we could not further follow up the referred study subjects with psychiatry department for confirmation of Dementia. Further Geriatric depression can be confirmed using Structured Clinical Interview for DSM-IV (SCID) a gold standard assessment. $^{17}$

\section{ACKNOWLEDGEMENTS}

We are thankful to all the staff of Community Medicine Department for the valuable inputs, We are thankful to all study participants and Bhagyashree A, Chaitra G, Chaitra K, Hemanth Kumar C, Kavyashree K, Mohammed Muffasil who were part of the study group.

Funding: No funding sources

Conflict of interest: None declared

Ethical approval: The study was approved by the Institutional Ethics Committee

\section{REFERENCES}

1. Park K. Textbook of Preventive and Social medicine. 21nd edition. Jabalpur: M/S Banarsidas Bhanot; 2011: 547-549.

2. Government of India. Census of India 2011. Population composition, chapter 2. 2011.

3. Shaji S, Bose S, Verghese A. Prevalence of dementia in an urban population in Kerala, India. The British J Psych. 2005;186(2):136-40.

4. Vas CJ, Pinto C, Panikker D, Noronha S, Deshpande N, Kulkarni L, Sachdeva S.Prevalence of dementia in an urban Indian population. Int Psychogeriatr. 2001;13(4):439-50.

5. Chandra V, Ganguli M, Pandav R, Johnston J, Belle S, DeKosky ST. Prevalence of Alzheimer's disease and other dementias in rural India: The Indo-US study. Neurology. 1998;51:1000-8.

6. Shaji KS, Jotheeswaran AT, Girish N, Bharath S, Dias A, Pattabiraman M. Prevalence, impact, costs and services for dementia. A report prepared for the Alzheimer's and Related Disorders Society of India. The dementia INDIA report 2010.

7. Chauhan P, Kokiwar PR, Shridevi K, Katkuri S. A study on prevalence and correlates of Depression among elderly population of rural South India. Int J Community Med Public Health. 2016;3:236-9.

8. Rajkumar AP, Thangadurai P, Senthilkumar P, Gayathri K, Prince M, Jacob KS. Nature, prevalence and factors associated with depression among the elderly in a rural south Indian community. Intern Psychogeriatrics. 2009;21:372-8.

9. Vishal J, Bansal RK, Swati P, Bimal T. A study of depression among aged in Surat city. National J Comm Med. 2010;1(1):47-9.

10. Swarnalatha N. The prevalence of depression among the rural elderly in Chittoor District, Andhra Pradesh. J Clinical Diagn Res. 2013;7(7):1356-60.

11. Udayar SE, Prasad DV. Epidemiological study of socio demographic factors in relation to depression among the elderly people in a rural area of Chittoor 
district of Andhra Pradesh, India. Int J Community Med Public Health. 2016;3:161-5.

12. Shaji KS, Jithu VP, Jyothi KS. Indian research on aging and dementia. Indian $\mathrm{J}$ Psychiatry. 2010;52(Suppl 1):S148-52.

13. Sundru MB, Goru KB. Epidemiological study of depression among population above 60 years in Visakhapatnam, India. Int J Med Sci Public Health. 2013;2:695-702.

14. Ganguli M, Ratcliff G, Chandra V, Sharma S, Gilby J, Pandav R, Belle S, Ryan C, Baker C, Seaberg E, Dekosky S. A hindi version of the MMSE: The development of a cognitive screening instrument for a largely illiterate rural elderly population in India. Int J Geriat Psychiatry. 1995;10:367-7.

15. Geriatric depression scale: short version Available at

http://www.mhsfopcls.com/downloads/ger_dep_scl. pdf. Accessed on 26 March 2016.

16. Collin C, Wade DT, Davies S, Horne V. The Barthel ADL Index: a reliability study. Int Disability Study.1988;10:61-3.

17. Marc LG, Raue PJ, Bruce ML. Screening performance of the geriatric depression scale (GDS$15)$ in a diverse elderly home care population. Am J Geriatr Psychiatry. 2008;16(11):914-21.

18. Pandav R, Fillenbaum G, Ratcliff G, Dodge H, Ganguli M. Sensitivity and specificity of cognitive and functional screening instruments for dementia: The Indo-U.S. Dementia epidemiology study. J Am Geriatr Soc. 2002;50(3):554-61.

19. Rajkumar S, Kumar S. Prevalence of dementia in the community-a rural-urban comparison from Madras, India. Aus J Ageing. 1996;15:9-13.

20. Shaji S, Promodu K, Abraham T, Roy KJ, Verghese A. An epidemiological study of dementia in a rural community in Kerala. British J Psych. 1996;168:745-649.

21. Nandi PS, Banerjee G, Mukherjee SP, Nandi S, Nandi DN. A study of psychiatric morbidity of the elderly population of a rural community in west Bengal. Indian J Psychiatry. 1997;39:122-9.

22. Jain RK, Aras R. Depression in geriatric population in urban slums of Mumbai. Indian J Pub Health. 2007;51:112-3.

23. Tiwari SC, Srivastava S. Geropsychiatric morbidity in rural Uttar Pradesh. Indian $\mathbf{J}$ Psychiatry. 1998;40:266-73.

24. Rao AV, Virudhagirinathan BS, Malathi R. Mental illness in patients aged fifty and over. Indian $\mathbf{J}$ Psychiatry. 1972;14:319-32.

25. Sengupta P, Benjamin AI. Prevalence of depression and associated risk factors among the elderly in urban and rural field practice areas of a tertiary care institution in Ludhiana. Indian $\mathbf{J}$ of Pub Health. 2015;59(1):3-8.

26. Barua A, Acharya D. Depression in elderly: A cross-sectional study in rural south India. JIMSA. 2007;20(4):259-61.

27. Taqui AM, Itrat A, Qidwai W, Qadri Z. Depression in the elderly: Does family system play a role? A cross-sectional study. BMC Psychiatry. 2007;7:57.

28. Steffens DC, Otey E, Alexopoulos GA, Butters MA, Cuthbert B, Ganguli $\mathrm{M}$, et al. Perspectives on depression, mild cognitive impairment and cognitive decline. Arch Gen Psychiatry. 2006;63:130-8.

29. Ganguli M. Depression, cognitive impairment and dementia: Why should clinicians care about the web of causation? Indian J Psychiatry. 2009;51(Suppl 1):S29-34.

30. Ganguli M, Dodge HH, Mulsant BH. Rates and predictors of mortality in an aging, rural, community-based cohort: The role of depression. Arch Gen Psychiatry. 2002;59:1046-52.

Cite this article as: Sumana M, Sreelatha CY, Sreeranga A, Arpitha B, Akshatha SP, Anand HD. Prevalence of dementia and other psychiatric morbidities among geriatric population of Salagame primary health centre in Hassan district, Karnataka, India. Int J Community Med Public Health 2016;3: 1315-7. 